\title{
Recall and articulation of English and Chinese words by Chinese-English bilinguals
}

\author{
HIM CHEUNG and SUSAN KEMPER \\ University of Kansas, Lawrence, Kansas
}

\begin{abstract}
Three groups of subjects were tested to investigate the effect of language on the relationship between recall span and articulation rate. Native English-speaking monolinguals and native Chinese-speaking monolinguals recalled only English or Chinese words, respectively. ChineseEnglish bilinguals recalled both English and Chinese words. Articulation rates for English and Chinese monolinguals and Chinese-English bilinguals in each language were also obtained. When recall span was regressed on articulation rate, the slopes for Chinese and English words were significantly different for the Chinese-English bilinguals. This difference was not due to language proficiency but to phonological differences between English and Chinese.
\end{abstract}

A persistent finding in contemporary memory research has been that there is a relationship between short-term recall and speaking rate. Baddeley, Thomson, and Buchanan (1975) demonstrated that immediate verbal recall is limited to what can be pronounced in approximately $1.8 \mathrm{sec}$; this relationship has been shown to hold for a wide range of ages and materials (Case, Kurland, \& Goldberg, 1982; Hulme, Thompson, Muir, \& Lawrence, 1984; Kynette, Kemper, Norman, \& Cheung, 1990; Nicolson, 1981; Schweickert \& Boruff, 1986; Standing, Bond, Smith, \& Isely, 1980). The relationship between speech rate and immediate recall has been attributed to an "articulatory loop" - an articulatory control process that helps refresh verbal materials stored in a short-term phonological store (Longoni, Richardson, \& Aiello, 1993). Information in the phonological store is subject to decay; however, an articulatory rehearsal process can reactivate it. Recall is thus determined by articulation, in that recall is limited to the amount of information that can be rehearsed before it decays from the phonological store.

The articulatory loop model is supported by a variety of findings: recall spans are shorter for longer words requiring more time to pronounce (Baddeley et al., 1975), and concurrent articulation suppresses rehearsal and impairs recall (Baddeley, Lewis, \& Vallar, 1984). The most convincing evidence favoring the articulatory loop model can be found in studies of recall and articulation in languages other than English. Ellis and Hennelly (1980) tested Welsh-English bilinguals on digit spans as well as digit articulation rates for both languages. Welsh digits took longer to articulate than English digits, and the

This research was submitted by the first author in partial fulfillment of the requirements for the MA degree. Special thanks are given to James I. Chumbley, who offered useful suggestions on revising the manuscript. Reprint requests may be addressed to $\mathrm{H}$. Cheung, Depart ment of Psychology, 426 Fraser, University of Kansas, Lawrence, KS 66045 subjects had correspondingly smaller digit spans in Welsh than in English. Hoosain (1982) tested Chinese- English bilinguals on digit span and speed of pronunciation. The absolute digit span in Cantonese was 9.9, whereas that for English was 7.3. This larger Cantonese digit span was accompanied by faster articulation. Zhang and Simon (1985) also found that word length affects Chinese recall span; the average recall span for one-syllable words composed of a single character was 6.4 , whereas that for twosyllable words composed of two characters was 3.8 . Zhang and Simon also found evidence that another shortterm store, perhaps corresponding to the visuospatial sketchpad described by Baddeley (1986), contributes to recall span in Chinese, since an average of 2.7 radicals (nonpronounceable components of characters) was also recalled.

The present experiment was undertaken to examine how linguistic differences affect recall spans and articulation rates. Specifically, we studied how word length affects both articulation and recall span in two different languages. Within-subject comparisons were performed by examining recall spans and articulation rates for Chinese-English bilinguals in both English and Chinese. Articulation rates for one-, two-, and three-syllable words in both languages were obtained, as were recall spans for one-, two-, and three-syllable words in both languages. Articulatory suppression was used with the word recall task to reveal the residual effect of any nonphonologically based store on the recall of Chinese words. Finally, the performance of the bilinguals was compared with that of Chinese or English monolinguals to determine how linguistic proficiency affects the relationship between recall span and articulation.

\section{METHOD}

\author{
Subjects \\ Three groups of subjects were tested. Group 1 comprised 18 male \\ and 18 female undergraduates at the University of Kansas who were \\ native American-English speakers. All were students in an introduc-
}


tory psychology course who volunteered for this experiment for course credit.

Thirty-six female students at the Hong Kong Polytechnic were tested as Group 2. They were all native Cantonese-Chinese speakers without much training in English. They participated in the experiment voluntarily without any reward. Their English ability was assessed according to a brief personal history, which detailed their exposure to and use of English, and by self-ratings of oral English fluency and listening, reading, and writing abilities in English. A five-point scale was used where $1=$ very bad and $5=$ excellent; self-report ratings ranged from a total of 4 to a total of 13 (maximum $=20$ ), with a mean of 8.03 . None of the subjects had taken the Test of English as a Foreign Language (TOEFL). None had resided outside of Hong Kong for more than 1 month. This group was considered to be monolingual. Polytechnic male students were excluded, since most had significant training in English.

Group 3 consisted of undergraduates and graduate students at the University of Kansas who were Chinese-English bilinguals with native Cantonese-Chinese fluency (or native Mandarin-Chinese in three cases). There were 18 males and 18 females. All of these bilinguals voluntarily participated in the experiment without any reward. Their English language abilities were assessed according to two criteria. First, each subject's TOEFL score was elicited. Second, the subject completed a brief personal history, which detailed his/her exposure to and use of English; each also rated his/her own oral English fluency, and listening, reading, and writing abilities in English. A five-point scale was used, where $1=$ very bad and $5=$ excellent. The TOEFL scores ranged from 433 to 590 , with a mean of 536; the self-report ratings ranged from a total of 6 to a total of 17 (maximum $=20$ ), with a mean of 13 .

\section{Tasks}

Each subject was tested separately, and two experimental tasks, a recall task and an articulation task, were administered to each subject in this experiment. The order of English and Chinese trials was blocked and counterbalanced across subjects in Group 3.

Recall. The subjects read lists of words presented sequentially and then attempted to recall the words in the correct serial order. Each list consisted of seven words of the same length-one, two, or three syllables. The individual words were printed on file cards, and the seven cards of each list were presented sequentially by the experimenter at a rate of seven cards per $5 \mathrm{sec}$. Each card was placed on top of the preceding card in a stack before the subject. A final blank card after the seventh card signaled the end of a list and that the subject was to begin serial recall of the list. Response forms were provided so that the subjects could record their recall.

Table 1

Examples of the One-, Two-, and Three-Syllable English and Chinese Words

\begin{tabular}{ccll} 
Language & $\begin{array}{c}\text { Number of } \\
\text { Syllables }\end{array}$ & & Words \\
\hline English & 1 & $\begin{array}{l}\text { pit } \\
\text { soup } \\
\text { coming } \\
\text { rabbit } \\
\text { foreigner } \\
\text { following }\end{array}$ & $\begin{array}{l}\text { fur } \\
\text { hint } \\
\text { defect } \\
\text { posture } \\
\text { conjunction } \\
\text { explosion }\end{array}$ \\
Chinese & 2 & $\begin{array}{l}\text { yiu } \\
\text { gon } \\
\text { tong fu } \\
\text { yi chi } \\
\text { pao mud sin } \\
\text { tai chi yin }\end{array}$ & $\begin{array}{l}\text { man } \\
\text { chow yu } \\
\text { choi yang } \\
\text { fong che yip } \\
\text { ba chiu fa }\end{array}$ \\
\hline
\end{tabular}

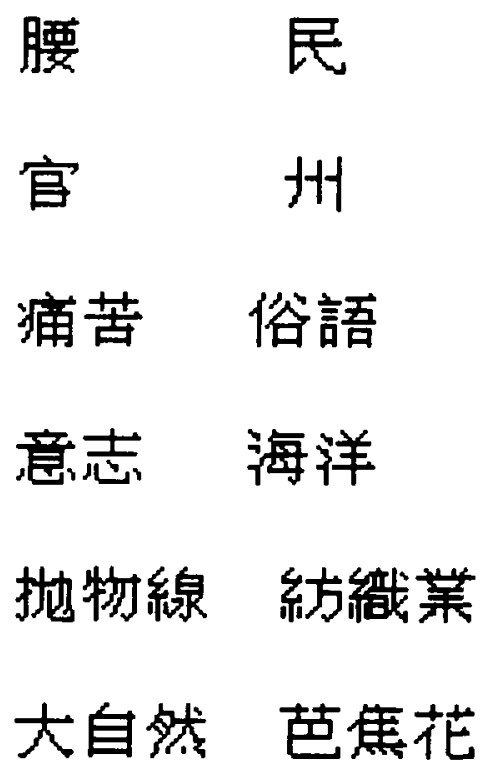

Figure 1. Examples of the one-, two-, and three-character Chinese words.

Two variants of the recall task were used. In the no-suppression condition, the subjects read silently and then recalled the words. In the suppression condition, the subjects were asked to repeat aloud the digits " $1,2,3,4$ " while reading the words and while recalling them. Five different lists were tested for each length in each condition. Each subject's recall span in each condition was defined as the median number of words recalled on the five lists of seven words; the maximum was seven. English and Chinese trials were blocked and counterbalanced across subjects in Group 3.

Articulation. The subjects were shown a pair of words of one, two, or three syllables, and they were asked to repeat aloud the word pairs as rapidly as possible. Each word pair was repeated 20 times. The subjects' repetitions were audio recorded. The subjects were tested on three pairs at each length; the lengths were ordered across subjects according to a Latin square procedure. A stopwatch was used to measure the total articulation time of the middle 10 repetitions of each word pair. Each set of 10 repetitions of a word pair was timed three times, and the median articulation time was computed for each word pair. Words-per-second articulation rates were calculated for each subject in each condition as the median of the three pairs tested at each length.

\section{Materials}

For the recall task, 70 one-syllable, 70 two-syllable, and 70 threesyllable English words were selected. The 70 words at each length were divided into two sets to construct the different stimulus lists, and these two sets were counterbalanced across suppression conditions. For the articulation task, three one-syllable, three twosyllable, and three three-syllable English word pairs were selected. To control for word familiarity, the English words used in the different conditions for the recall task were matched for occurrence frequency (Francis \& Kučra, 1982) $[t(68)<1.05, p>.10]$. Word frequencies ranged from 22 to 86 occurrences per 1,000 words. The word pairs used in the articulation task were also matched for occurrence frequency. The three pairs at each length had occurrence frequencies of 17,19 , and 21 occurrences per 1,000 words.

A set of 70 one-syllable, 70 two-syllable, and 70 three-syllable Chinese words was selected for the recall task, and three one- 
syllable, three two-syllable, and three three-syllable Chinese word pairs were selected for the articulation task. These Chinese words were selected from a word frequency list compiled by the Hong Kong Department of Education (1986), so that the occurrence frequencies of the one-, two-, and three-syllable words did not differ $[t(68)<2.00, p>.10]$. In the recall task, the 70 Chinese words at each length were divided into two sets to construct the different lists, and these two sets were counterbalanced across suppression conditions.

In Chinese, words are made up of characters, and each character has one and only one syllable. Therefore, one-, two-, and threesyllable words correspond to one-, two-, and three-character words, respectively. The occurrence frequencies of the English words and those of the Chinese words were also matched. In all conditions, English and Chinese words did not differ in occurrence frequency $[t(68)\langle 1.30, p\rangle .10]$. Thus, any between-language difference in recall or articulation rates could not be attributed to differences in word frequency. Examples of the stimuli are given in Table 1 and Figure 1.

\section{RESULTS}

For each group, a mean recall score and a mean articulation rate (words/second) were obtained in each condition. These means are presented in Table 2. (A summary of the analysis of variance [ANOVA] results for the recall span and aritculation rates is available from the first author.)

Mean recall scores for one-, two-, and three-syllable words were regressed on the median articulation rates for one-, two-, and three-syllable words for each subject individually; recall scores in the suppression condition were analyzed separately from those in the no-suppression condition. Each language was separately analyzed for the

Table 2

Mean Recall Spans and Articulation Rates (Words/Second) in Groups 1, 2, and 3

\begin{tabular}{llcr} 
& \multicolumn{3}{c}{ Word Length (Syllables) } \\
\cline { 2 - 4 } Measure & 1 & 2 & 3 \\
\hline
\end{tabular}

Recall span

Group 1: English Monolinguals

Suppression

$\begin{array}{ll}1.64 & 1.67 \\ 2.64 & 2.36 \\ 3.03 & 2.53\end{array}$

1.22

Articulation rates

1.72

1.98

Group 2: Chinese Monolinguals

Recall Span

$\begin{array}{llll}\text { Suppression } & 1.83 & 0.90 & 0.69 \\ \text { No Suppression } & 4.14 & 1.56 & 1.33 \\ \text { Articulation Rates } & 4.06 & 2.55 & 1.75\end{array}$

Recall span, English

Group 3: Chinese-English Bilinguals

\begin{tabular}{llll}
$\begin{array}{l}\text { Suppression } \\
\text { No suppression }\end{array}$ & 0.67 & 0.36 & 0.17 \\
$\begin{array}{l}\text { Recall span, Chinese } \\
\text { Suppression }\end{array}$ & 1.39 & 0.83 & 0.67 \\
$\begin{array}{l}\text { No suppression } \\
\text { Articulation rates }\end{array}$ & 1.47 & 0.64 & 0.36 \\
English & 4.06 & 1.29 & 1.28 \\
Chinese & & & \\
\hline
\end{tabular}

Note-Recall span for each subject was the median number of words recalled on the five lists of seven words.

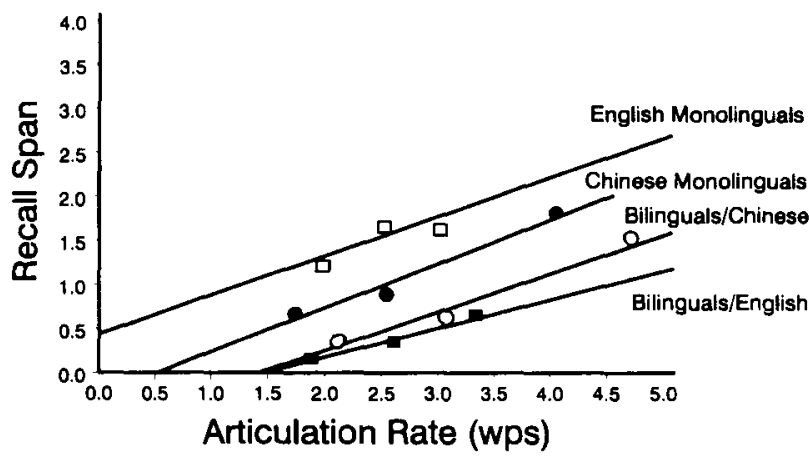

Figure 2. Recall span as a function of articulation rate for English words by English monolinguals, Chinese words by Chinese monolinguals, and English and Chinese words by Chinese-English bilinguals with articulatory suppression.

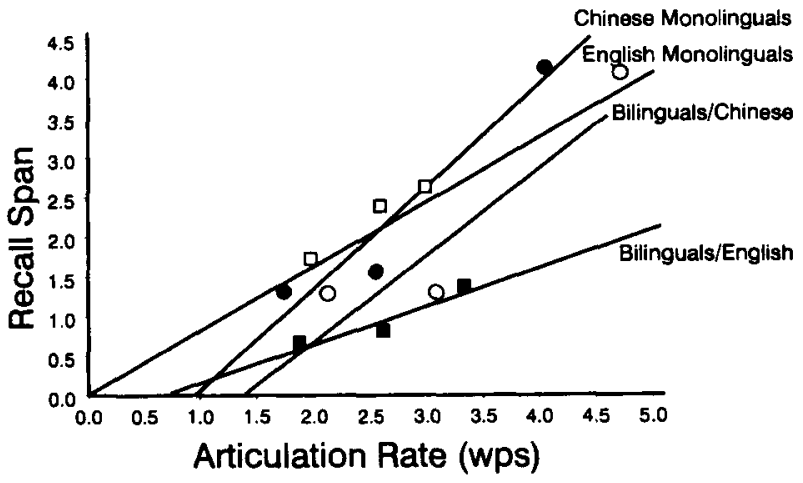

Figure 3. Recall span as a function of articulation rate for English words by English monolinguals, Chinese words by Chinese monolinguals, and English and Chinese words by Chinese-English bilinguals without articulatory suppression.

bilingual subjects in Group 3. Figures 2 and 3 plot the results for the suppression and no-suppression conditions, respectively. Table 3 presents the mean betas, intercepts, and $R^{2}$ s for each suppression condition. The betas indicate the increase in recall span resulting from an increase in articulation rate.

For Group 3, the betas were subjected to a two-way within-subject ANOVA with condition and language as the independent factors. The effect of condition was significant $\left[F(1,35)=12.31, M S_{\mathrm{e}}=0.58, p<.002\right]$. The slopes for recall were greater in the no-suppression condition $(M=.83)$ than in the suppression condition $(M=$ .38). More interesting is the significance of the withinsubject language effect $\left[F(1,35)=12.72, M S_{e}=0.28\right.$, $p<.002$ ]; slopes for Chinese words were significantly greater than those for English words. The two-way interaction was also significant $\left[F(1,35)=4.61, M S_{\mathrm{e}}=0.44\right.$, $p<.040]$. This interaction can be understood by examining the language simple effect under each suppression condition. Under the suppression condition, the effect of 
Table 3

Mean Betas, Intercepts, and $R^{2}$ s After Regressing Individual Subjects' Recall Spans on Their Articulation Rates

\begin{tabular}{|c|c|c|c|}
\hline Condition & $\beta$ & Intercept & $R^{2}$ \\
\hline \multicolumn{4}{|c|}{ Group 1: English Monolinguals } \\
\hline Suppression & 0.41 & 0.27 & 0.54 \\
\hline No Suppression & 0.95 & -0.47 & 0.52 \\
\hline \multicolumn{4}{|c|}{ Group 2: Chinese Monolinguals } \\
\hline Suppression & 0.52 & -0.36 & 0.69 \\
\hline No Suppression & 1.17 & -1.20 & 0.83 \\
\hline \multicolumn{4}{|c|}{ Group 3: Chinese-English Bilinguals } \\
\hline English & & & \\
\hline Suppression & 0.34 & -0.56 & 0.69 \\
\hline No Suppression & 0.55 & -0.58 & 0.65 \\
\hline \multicolumn{4}{|l|}{ Chinese } \\
\hline Suppression & 0.42 & -0.55 & 0.79 \\
\hline No Suppression & 1.10 & -1.40 & 0.82 \\
\hline
\end{tabular}

language was not significant $[F(1,35)=0.44, p>.5]$; in the no-suppression condition, however, the effect of language was highly significant $\left[F(1,35)=11.38, M S_{\mathrm{e}}=\right.$ $0.48, p<.003]$. The slopes regressing recall on articulation rates were significantly greater for Chinese than for English words in the no-suppression condition, but articulatory suppression eliminated this difference. The slopes for English and Chinese words under articulatory suppression were both significantly different from zero [English, $t(35)=3.47, p<.01$, two-tailed; Chinese, $t(35)=5.61, p<.01$, two-tailed]. The intercepts were also subjected to a $2 \times 2$ within-subject ANOVA. None of the effects was significant [language, $F(1,35)=3.39$, $p>.05$; condition, $F(1,35)=1.63, p>.05$; interaction, $F(1,35)=1.81, p>.05$ ].

Cross-group comparisons of the betas and intercepts were also performed. First, to test for an effect of English proficiency, the mean beta from Group 1 was compared with the mean beta in the English condition from Group 3 for each suppression condition. Neither comparison was significant [suppression, $t(70)=0.36, p>.70$, twotailed; no suppression, $t(70)=1.42, p>.15$, twotailed]. For Group 1, the slope under articulatory suppression was significantly different from zero $[t(35)=2.94$, $p<.01$, two-tailed]. Second, to test for an effect of Chinese proficiency, the mean beta from Group 2 was compared with the mean beta in the Chinese condition from Group 3 for each suppression condition. Neither comparison was significant [suppression, $t(70)=0.94$, $p>.35$, two-tailed; no suppression, $t(70)=0.29$, $p>.25$, two-tailed]. For Group 2, the slope under articulatory suppression was significantly different from zero, $[t(35)=6.78, p<.01$, two-tailed].

The same cross-group comparisons were also done on the mean intercepts. Only the difference between the groups for English words in the suppression condition was significant $[t(70)=2.04, p<.05$, two-tailed]. The intercepts for native English speakers were somewhat greater than those for Chinese-English bilinguals in the English suppression condition.
To clarify these findings, articulation rates in words/ second were regressed on word length. The betas now reflected the decrease in articulation rate resulting from a one-syllable increase in word length. Means of betas, intercepts, and $R^{2}$ s are presented in Table 4 and plotted in Figure 4.

For Group 3, the betas were subjected to a two-way within-subject ANOVA with language as the independent factor. A significant language effect was found $[F(1,35)=$ $\left.92.34, M S_{\mathrm{e}}=0.06, p<.001\right]$. For the bilingual group, the decrease in articulation rate resulting from increasing word length was greater for Chinese words than for English words. The intercepts were subjected to a similar ANOVA. Language was again significant $[F(1,35)=$ $148.18, M S_{\mathrm{e}}=0.39, p<.001 \mathrm{~J}$. Intercepts in the Chinese condition were greater than those in the English condition.

To determine whether the difference was due to English proficiency, the mean betas and intercepts were compared for Group 1 and the English condition of Group 3. Both comparisons were significant $[\beta, t(70)=3.65, p<.001$, two-tailed; intercept, $t(70)=-2.96, p<.005$, twotailed]. For English words, the slopes and intercepts derived from the bilinguals were greater than those derived from the native English speakers. The mean betas and intercepts for Group 2 were compared with those for the Chinese condition of Group 3 to test for an effect of

Table 4

Mean Betas, Intercepts, and $\boldsymbol{R}^{2} \mathbf{s}$ After Regressing Individual Subjects' Articulation Rates on the Number of Syllables

\begin{tabular}{lccc}
\hline \multicolumn{1}{c}{ Group } & $\beta$ & Intercept & $R^{2}$ \\
\hline 1: English monolinguals & -0.52 & 3.56 & 0.92 \\
2: Chinese monolinguals & -1.15 & 5.09 & 0.95 \\
3: Chinese-English bilinguals & & & \\
$\quad$ English & -0.73 & 4.07 & 0.89 \\
Chinese & -1.30 & 5.87 & 0.96 \\
\hline
\end{tabular}

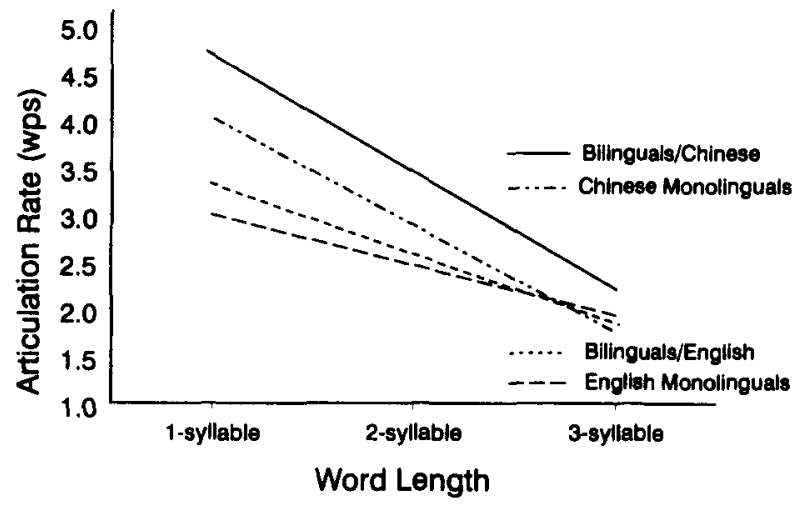

Figure 4. Articulation rate as a function of word length for English words by English monolinguals, Chinese words by Chinese monolinguals, and English and Chinese words by Chinese-English bilinguals. 
Chinese proficiency. Both comparisons were again significant $[\beta, t(70)=2.32, p<.03$, two-tailed; intercepts, $t(70)=-4.26, p<.001$, two-tailed]. The slopes and intercepts derived from the bilinguals were greater than those derived from the Chinese monolinguals.

\section{DISCUSSION}

The articulatory loop model formulated by Baddeley (1986) predicts a positive linear relationship between articulation rate and short-term recall span. This linear relationship was found for both English and Chinese monolinguals, as well as for Chinese-English bilinguals in either language, indicating some degree of universality for this relationship. However, further analyses revealed some language-specific differences. First, for the bilingual subjects, increasing articulation rates by a fixed amount was found to be associated with a larger increase in the recall of Chinese words than in that of English words. This represents a quantitatively different short-term store for Chinese words that cannot be directly due to differences in articulation rate. Since articulatory suppression abolished this language effect, it appears that articulating Chinese words activates another encoding process, either a nonarticulatory phonological store (Baddeley \& Lewis, 1981 ) or a visuospatial store (Zhang \& Simon, 1985).

Second, the recall span-articulation rate relationship depends on the linguistic characteristics of the verbal stimuli rather than on the linguistic proficiency of the subjects. Although native English proficiency boosted the overall recall of English words, resulting in a difference in the intercepts between Groups 1 and 3, and although the bilingual subjects were relatively slower with respect to articulating either English or Chinese words when they were compared with monolinguals, no group differences were found for the slopes when recall span was regressed on articulation rate.

Third, linguistic proficiency does affect articulation rate, since significant group differences were found when articulation rate was regressed on word length. Furthermore, the effect of decreasing word length on articulation rate for the bilinguals was significantly greater for Chinese words than for English words. The syllabic structure of the Chinese and English words used in the articulation task appears to affect the relationship between articulation rate and word length in the two languages. Chinese one-syllable words have a consonant-vowel, CV, or consonant-vowel-consonant, CVC, structure; consonant clusters rarely occur in Chinese. English one-syllable words often involve word-initial or word-final consonant clusters. Multisyllabic Chinese words preserve the simple $\mathrm{CV}$ repetition and multisyllabic English words approach this sample simple CVCVC or CVCVCVC pattern. The lack of consonant clusters and, typically, word-final consonants apparently contributed to the articulatory advantage of one-syllable Chinese words over one-syllable English words. As Chinese and English syllabic structure becomes more comparable as word length increases, the articulatory advantage for Chinese words over English words is reduced.

This research has confirmed the "universality" of the linear relationship between recall span and articulation rate by both within-subject and between-subject comparisons of English and Chinese. It has also revealed two languagespecific differences: (1) The recall of Chinese words is enhanced by either a visual iconic or a nonarticulatory phonological encoding process, and (2) differences in the syllabic structure of Chinese and English words affect articulation rate.

\section{REFERENCES}

BadDeley, A. D. (1986). Working memory. Oxford: Oxford University Press.

BADDELEY, A. D., \& LewIS, V. J. (1981). Inner active processes in reading: The inner voice, the inner ear and the inner eye. In $A . M$. Lesgold \& C. A. Perfetti (Eds.), Interactive processes in reading (pp. 107-129). Hillsdale, NJ: Erlbaum.

Baddeley, A. D., Lewis, V. J., \& Vallar, G. (1984). Exploring the articulatory loop. Quarterly Journal of Experimental Psychology, 36, 233-252.

Baddeley, A. D., Thomson, N., \& Buchanan, M. (1975). Word length and the structure of short-term memory. Journal of Verbal Learning \& Verbal Behavior, 14, 575-589.

Case, R., Kurland, D. M., \& Goldberg, J. (1982). Operational efficiency and growth of short term memory span. Journal of Experimental Child Psychology, 33, 386-404.

Ellis, N. C., Hennelly, R. A. (1980). A bilingual word-length effect: Implications for intelligence testing and the relative ease of mental calculation in Welsh and English. British Joumal of Psychology, 71, 43-51.

FranCIS, W. N., \& KuCERA, H. (1982). Frequency analysis of English usage. Boston: Houghton Mifflin.

Hong Kong Department of Education (1986). A study of Chinese words used by Hong Kong junior high school students. Hong Kong: Author.

Hoosain, R. (1982). Correlation between pronunciation speed and digit span size. Perceptual \& Motor Skill, 55, 1128

Hulme, C., Thompson, N., Muir, C., \& Lawrence, A. (1984). Speech rate and the development of short-term memory span. Journal of Experimental Child Psychology, 38, 241-253.

Kynette, D., Kemper, S., Norman, S., \& Cheung, H. (1990). Adults' word recall and word repetition. Experimental Aging Research, 16, 117-121

Longoni, A. M., Richardson, J. T. E., \& Aiello, A. (1993). Articulatory rehearsal and phonological storage in working memory. Memory \& Cognition, 21, 11-22.

Nicolson, R. (1981). The relationship between memory span and processing speed. In M. Friedman, J. P. Das, \& N. O'Connor (Eds.), Intelligence and learning (pp. 179-184). New York: Plenum.

SCHWEICKERT, R., \& BoRUFF, B. (1986). Short-term memory capacity: Magic number or magic spell? Journal of Experimental Psychology: Learning. Memory, \& Cognition, 12, 419-425.

Standing, L., Bond, B., Smith, P., \& Isely, C. (1980). Is the immediate memory span determined by subvocalization rate? British Joumal of Psychology, 71, 525-539.

Zhang, G., \& Simon, H. A. (1985). STM capacity for Chinese words and idioms: Chunking and acoustical loop hypotheses. Memory \& Cognition, 13, 193-201.

(Manuscript received August 10, 1992; revision accepted for publication April 2, 1993.) 